\title{
Factors Influencing Using Self-Directed Learning among Technical Nurses Students in Maternal \&Neonatal Nursing Course
}

\author{
Eman Galal Mohamed, Nabila Taha Ahmed \& Fatma Aboul Khair. \\ Technical Instructor at Technical Health Institute of Nursing, Police Authority Hospital Egypt. \\ Professor of Obstetrics and Gynecological Nursing, Faculty of Nursing, Assiut University, Egypt. \\ lecturer Maternity and Neonatal Nursing, Faculty of Nursing, Fayoum University, Egypt.
}

\begin{abstract}
Background: Research on nursing students showed that adopting self-directive learning of effort, time, and study environment can positively influence academic achievements for undergraduate students and use of self-learning packages. Aim of the study: Identifying factors that affect the using of self-directive learning among technical nurses' students in maternal \& neonatal course Nursing Institute Fayoum University. Subject and methods: A descriptive study design was used to achieve the aim of the study. Included two groups; the $1^{\text {st }}$ included 50 students $\&$ the $2^{\text {nd }} 7$ instructors during the $1^{\text {st }}$ semester (October 2013/2014) from the pre-mentioned institute. Sample type: a convenient sample Tools: Interviewing questionnaire sheet to assess samples characteristics'\& Opinionnaire sheet to assess the students' and instructors'. Opinions regarding factors affecting using of self-directive learning. Results: all students and instructors have past knowledge and practice about the computer use, student's views includes 98\% student's language abilities and $96 \%$ clarity aim of the package\& clarity content are the most of important factors contribute to use self-directed learning, $100 \%$ of students recommended providing suitable time for package and $100 \%$ of instructors recommended suitable time for package, procedures should be clear and interesting images, Institution administration, Program innovation, and availability of resources. Conclusion: Clarity of the topics, organization, student language level, teacher characteristics, academic abilities and availability of resources among factors can facilitating or hindering the use of self-directive learning approach. Recommendations: Nursing institution administrators must support teacher and student by creating an environment conducive to implement selfdirective learning.
\end{abstract}

\section{Keywords: Self-Directed Learning, Nursing Student Institution, Factors, Facilitate \& Hinder.}

\section{Introduction}

A recent concept in quality of nursing education is self-directed learning (SDL), which is now considered to be a pillar of education (Montalvo \& Torres,2010 ). Educational self-direction is of interest to educators and psychologists. Researchers now apply self-direction principles to academic study and other forms of learning, such as social and motor skills (Boekaerts et al., 2009), (Zimmerman, 2009). Therefore academic institutions are driven to increase retention and improve academic success. To that end, institutions attempt to effectively connect with students at various points in their academic careers to provide interventions, if needed, to promote retention and success (Guiffrida, Lynch, Wall, \& Abel, 2013).

The concept of self-direction was first introduced in the social cognitive theory of Bandura Bandura, (2010). The main assumption of this theory is that each person is the outcome of personal, environmental, and behavioral variables (Bandura. 2010), Bandura, (2011.).

Zimmerman \& Pons, (2010) defined SDL strategies as learning which the learners personally initiate and conduct instead of relying on educators, parents, or other educational factors. Pintrich (Pintrich, 2011) defines SDL as an active, constructive process by which the learners set goals, monitor their learning, and control their motivation, behavior, and cognition. Medical students especially nursing must use key self-regulating skills in clinical courses that involve specialized aspects such as dealing with patients, meaningful learning, use of critical thinking, selfassessment of activities, and need for updating personal information (Woods et al., 2011). A study of college students showed that effective teaching methods such as problem-based learning (PBL) provide opportunities for participation in SDL (Woods et al., 2011). Randi, (2011) found that selfdirective by teachers in the classroom can cause learners to self-regulate. Self-learning as a dependent variable can be influenced by gender, educational environment, teaching methods, personality family background, and other variables

Strage, (2012) This means that self-learning will be different in different contexts Deci \& Ryan, ( 2012). Students participating in clinical courses have a back ground in academic studies and are experiencing the last stages of official academic education in which 
they can learn the skills necessary to be lifelong learners (Al Kadri et al., 2012). Sandars \& Cleary, (2011) stated that integration of self-learning into the medical curriculum makes it possible to improve the clinical skills of medical students. Also, he considers most theoretcal self-learning to be applicable to medical education The varieties of student activities during this period, especially at the bedside, provide different circumstances for training Dunn, Osborne \& Link, (2012).

Rapid scientific and technological advances in health care mean that nurses need to keep learning and engage in professional education so that they can continue to provide safe and quality care. Education programs which prepare nurses for practice as a registered nurse have a vital role to play in ensuring that graduates are self-directed in responding to the need for ongoing learning throughout their professional career. Improving students' readiness for self-directed learning has thus gained increasing recognition as being an important goal of nursing education programs. In order to integrate effective self-directed learning a number of factors that influenced the outcomes of these learning activities, including teacher-student interaction, facilitation process and learning resources must be studied and assessed to provide effectively use.

\section{Significant of the Study}

Shortcomings of traditional methods used to prepare undergraduate nursing students for the increasingly demands and challenges of current healthcare environment, hence, the technical nursing institutions rationale for developing their vision of nursing program curricula. Clinical courses are required of all nursing students and mean that they must develop the key skill of self-regulation during learning. Nursing education programs now place a much greater importance on self- directed learning as new approaches in education, in particular, self- learning package, believing it is useful for learners to be given the skills to effectively search for, examine, apply new knowledge and accomplishment of personal development. Encouraging students to become involved in developing course requirements also increases their internal motivation to learn. The more control students have in their learning process, the more they sharpen their ability to sort through presented information as well as critically reflect and analyze their performance Herman, (2012). Therefore it is very important to promote self-directive learning in our students and study the factors facilitating and hindering implementation of this approach and how can our institution student and teacher recommend to facilitate self-directive learning.

\section{Aim of the study Wto}

- Identify factors that affecting the use of selfdirected learning among technical nurses' students in Maternal-Neonatal Nursing.

\section{Research Question}

What are the factors affecting the use of self-directed learning among technical nurses' students in maternal-neonatal nursing course?

\section{Subjects \& Methods}

- A descriptive study design was used to achieve the aim of the study. The study conducted in the classroom and the nursing skills' lab at Technical Nursing Institute, Fayoum University.

- A sample size of the study included two groups; the $1^{\text {st }}$ all second year nursing students, enrolled in obstetric nursing course, during the academic year 2013-2014 included 50 nursing student's during the $1^{\text {st }}$ semester (October 2013) $\&$ the $2^{\text {nd }}$ sample includes 7instructors from the pre-mentioned institute.

\section{Tools used for data collection were}

\section{Interview Questionnaire sheet}

This sheet was developed by the researcher, based on the reviewing of the related literature and guided supervisors. This sheet used for the instructors and students to explore age, degree of education for the students and previous experience in maternity course.

\section{Opinionnaire sheet}

This sheet was developed by the researcher, based on the reviewing of the related literature and guided supervisors. This sheet was filled by the instructors and students to identify from their views factors affecting the use of self-directed learning among technical nurses' students in maternity course and their recommendations to improve the implementation of this method in in maternity course Pilot Study

Pilot study was carried out on (10 students) $10 \%$ of the study students. The pilot study was done to ensure clarity, applicability, feasibility of the study tools, and time needed for each tool to be filled in. Instructors and students included in pilot study were not excluded from the sample because they not excluded from the registration in the course and there were no major modification ended in the tool of data collection based on the finding of pilot study

\section{Field work}

- The process of data collection was carried out in period of obstetrics and gynecology nursing course from October 2013to June 2014, and those students passed with previous experience of in maternity course. Students were asked to fill the opinionnaire sheet at the end of the course. 
- The study was carried out in three stages, planning, implementation, and evaluation. Planning Phase The researcher designed the questionnaire and opinionnaire by the researcher based literature review. Implementation Phase: The researcher asked the students to fill the questionnaire and opinionnaire sheet that help to detect factors affecting the use of self-directed 1 after implementation and examination the method in their course study. Evaluation phase: The researchers collect and analyzed data for each group.

\section{Results}

Table (1): Demographic Information of Students.

\begin{tabular}{|l|c|c|}
\hline \multicolumn{1}{|c|}{ Items } & Students (N=50) & Instructors(N=7) \\
\hline \multicolumn{1}{|c|}{ N } & \multicolumn{2}{c|}{} \\
\hline Mean age in years + SD & $19.26 \pm .44$ & $26.8 \pm 0.9$ \\
\hline Students have secondary school certificate & 100 & - \\
\hline Have previous knowledge in computer & 100 & - \\
\hline Students haven't Learning Experiences in maternity course & 100 & - \\
\hline Mean past educational experience & - & $9.4 \pm 3.2$ \\
\hline
\end{tabular}

Table (2): Distribution of Factors Contributing to Effect Using of Self-Directed Learning (Students View).

\begin{tabular}{|c|c|c|}
\hline Factors Facilitating/ Hindering & \multicolumn{2}{|c|}{ Students View $(\mathbf{N}=\mathbf{5 0})$} \\
\hline Factors Related to Self-Learning Package & $\mathbf{N}$ & $\%$ \\
\hline Clarity of aim. & 48 & 96 \\
\hline Sufficient content & 46 & 92 \\
\hline Integration of curriculum. & 42 & 84 \\
\hline Clarity content. & 48 & 96 \\
\hline Sufficient encouragement. & 39 & 78 \\
\hline Assessment content. & 41 & 82 \\
\hline Time exposure to the method. & 38 & 76 \\
\hline \multicolumn{3}{|l|}{ Factors Related to Teacher } \\
\hline Explanation. & 42 & 84 \\
\hline Participation. & 42 & 84 \\
\hline Feedback. & 35 & 70 \\
\hline Teacher as a whole. & 40 & 80 \\
\hline \multicolumn{3}{|l|}{ Factors Related to Students } \\
\hline Language ability. & 49 & 98 \\
\hline Confidence. & 43 & 86 \\
\hline Learning motivation. & 45 & 90 \\
\hline Responsibility. & 42 & 84 \\
\hline \multicolumn{3}{|l|}{ Factors Related to Institution } \\
\hline Curriculum innovation. & 35 & 70 \\
\hline Resources. & 40 & 80 \\
\hline Skills lab. & 41 & 82 \\
\hline Physical environment. & 40 & 80 \\
\hline Administrative facilities. & 30 & 60 \\
\hline Time to be familiar. & 32 & 64 \\
\hline Computer lab. & 30 & 60 \\
\hline
\end{tabular}

\section{Ethical Consideration/}

The study methodology is safe for the student and the media used in the study will be related to the subject and build on scientific and ethical consideration as well the study environment motivated \& productive for learning and the students announced for approval.

\section{Statistical design}

Data entry and statistical analysis were done using Statistical for Social Science "SPSS" version 18. Data were presented using descriptive statistics in the form of frequencies and percentage. 
Table (3): Distribution of Factors Contributing To Effect Using of Self-Directed Learning (Instructors View).

\begin{tabular}{|c|c|c|}
\hline Factors Facilitating/ Hindering & \multicolumn{2}{|c|}{ Instructors View N=7 } \\
\hline Factors Related to Self-learning Package & $\mathbf{N}$ & $\%$ \\
\hline Clarity of aim. & 7 & 100 \\
\hline Sufficient content & 6 & 85.7 \\
\hline Integration of curriculum. & 5 & 71.4 \\
\hline Clarity content. & 7 & 100 \\
\hline Sufficient encouragement. & 5 & 71.4 \\
\hline Assessment content. & 4 & 57.1 \\
\hline Time exposure to the method. & 4 & 57.1 \\
\hline \multicolumn{3}{|l|}{ Factors related to teacher } \\
\hline Explanation. & 7 & 100 \\
\hline Participation. & 7 & 100 \\
\hline Feedback. & 6 & 85.7 \\
\hline Teacher as a whole. & 6 & 85.7 \\
\hline \multicolumn{3}{|l|}{ Factors related to students } \\
\hline Language ability. & 7 & 100 \\
\hline Confidence. & 6 & 85.7 \\
\hline Learning motivation. & 7 & 100 \\
\hline Responsibility. & 5 & 71.4 \\
\hline \multicolumn{3}{|l|}{ Factors related to Institution } \\
\hline Curriculum innovation & 4 & 57.1 \\
\hline Resources & 4 & 57.1 \\
\hline Skill lab & 7 & 100 \\
\hline Physical environment & 4 & 57.1 \\
\hline Administrative facilities & 3 & 42.8 \\
\hline Time to be familiar. & 3 & 42.8 \\
\hline Computer lab & 3 & 42.8 \\
\hline
\end{tabular}

Table (4): Students Recommendations to Facilitate Using Self-Directed Learning.

\begin{tabular}{|l|c|c|}
\hline \multicolumn{1}{|c|}{ Student's Recommendations } & \multicolumn{2}{c|}{ Students Group } \\
\cline { 2 - 3 } & $\mathrm{N}$ & 76.0 \\
\hline Interesting topic. & 38 & 80.0 \\
\hline Content is clear, simple, and well organized. & 40 & 100.0 \\
\hline Provide suitable time. & 50 & 90.0 \\
\hline Procedures are clear and interesting images. & 45 & 60.0 \\
\hline Good explanation \& guidance of the teacher. & 30 & 84.0 \\
\hline Teacher resection for student's ability. & 42 & 76.0 \\
\hline Clarity of examination and feedback. & 38 & \multicolumn{2}{c|}{} \\
\hline
\end{tabular}

Table (5): Instructors Recommendations to Facilitate Using Self-Directed Learning.

\begin{tabular}{|l|c|c|}
\hline \multicolumn{1}{|c|}{ Instructor's Recommendations } & \multicolumn{2}{c|}{ Instructor's Group } \\
\cline { 2 - 3 } & $\mathbf{N}$ & $\mathbf{\%}$ \\
\hline Interesting topic. & 4 & 57.1 \\
\hline Content is clear, simple, and well organized. & 7 & 100 \\
\hline Using of different media. & 6 & 85.7 \\
\hline Provide suitable time. & 7 & 100 \\
\hline Procedures are clear and interesting images. & 5 & 71.4 \\
\hline Institution administration. & 7 & 100 \\
\hline Program innovation. & 7 & 100 \\
\hline Availability of rescores. & 7 & 100 \\
\hline
\end{tabular}


Table (1): Showes that the mean age of the students group is $19.26 \pm .44$, while the mean age of instructors group was $26.8 \pm 0.9$.also the table shows all the students enter the technical institute from secondary school and they haven't previous experience in maternity course, and the result indicate that all students and instructors have past knowledge and practice about the computer use.

Table (2): Reveals student's view related factors contributing to effect the use self-directed learning the results indicated that $98 \%$ student's language abilities, $96 \%$ clarity aim of the package \& clarity content, 84\% teacher's participation \& explanation, $80 \%$ institutional resources\& physical environment are the most of the important factors contribute to use self-directed learning.

Table (3): Summarizes instructor's view related factors contributing to effect the use self-directed learning the results the results indicated that $100 \%$ of them reported clarity aim of the package \& clarity content, teacher's participation \& explanation, student's language abilities\& learning motivation and skill lab are the most of the important factors contribute to use self-directed learning.

Table (4): Represents student's recommendations to facilitate using self-directed learning $100 \%$ of them recommended providing suitable time for package. As well as $90 \%$ the procedures should be clear and interesting images.

Table (5): Reflects students recommendations to facilitate using self-directed learning the result shows $100 \%$ of instructors recommended suitable time for a package, procedures should be clear and interesting images, Institution administration, Program innovation, and availability of resources.

\section{Discussion}

Self-directed learning is essential in assisting nurses to meet the challenges presented in today's health care environment. Nurse educators have an important role in assisting nurses to acquire the skills for selfdirected learning and to do this they need to understand the concept of self-directed learning and factors that hindering or facilitating implementation of this approach in nursing courses. There are large numbers of influencing factors that can affect the implementation of self-directed learning related to self-learning process, self-direct learner, learning resources, and the facilitator. This current study aimed to identify factors that affecting the use of selfdirected learning among technical nurses' students in maternal \& neonatal nursing course which quoted from the study Self-learning Package versus Traditional Teaching for Postpartum Care: its Reflect on Student's Performance which implemented in
Technical Institute of Nursing - Fayoum University to summarize results of oppenionair sheet containing many factors related to instructors and students.

Concerning the general characteristics of studied sample groups instructors and students, the results showed that mean age of the student's group was, $19.26+.44$, while the mean age of instructors group was $26.8+0.9$. Over and above all the students enter the technical institute from secondary school and they haven't previous experience in maternity course. And the mean past educational experience for instructors was $9.4+3.2$. Also, the result of the study indicated that all instructors and student have basics skills in using a computer in a cadmic study.

The previous result agreed with (Farrag, 2010) who stated that the students and teachers considered their own computer skills level is an important factor that contributed to their use of Self-directed learning. Students and teachers with good computer skills gave positive statements about working with computers, while students and teachers with limited computer skills gave negative comments on working with computers that contributed factor affecting the use of self-directed learning.

The findings of the present study revealed that the variety of factors may have effects on the use of selfdirected learning. Firstly regarding the module itself; from the student views the majority of students reported that their language ability is an important factor that can hinder or facilitate the use of package, this result may be due to the all student in this study graduated from secondary school which mean they enter technical nursing institute with little or no previous relevant experience for English language, which gets them not able to use self-package without clarification, and also in their study in technical institute for English just as language not for medical content.

On the same line (Abdirahman, 2013) investigated the relationship between English language proficiency (as measured by the English language GPA the student obtains from his/her secondary school) and academic achievement (as measured by the student's GPA from the examination in the first semester). He found that the undergraduate students in Somalia, their academic success or failure is closely related to English language on the academic performance which prevented them to use new approaches in learning rather than traditional methods.

On the other hand the organization and clarity of the package aim' are the most important factors contributing to the use of self-directed learning, followed by sufficient and clarity of content and its self-assessment tests is very effective. This result may reflect because they used to use a course book 
comprehensive and difficulty handling without selfassessment to give them feedback about their level.

According to the constructivist theory of learning, students build their own understanding of a subject through engaged activities, rather than passively accepting information presented to them. Instructors can support students' constructivism by preparing a good content asking good questions, listening to students' needs, and creating environments that allow students to make choices that reinforce the overall goals for courses (Reeve, 2009). Conversely, when the instructors use a book or notes without good preparation and interesting design \& rigid assessment tools are used with no preparation, students lose control and autonomy over their learning, reducing their intrinsic motivation to learn (Flint \& Johnson, 2011).

Concerning their view regarding teacher as a factor they reported that the explanation from the teacher, feedback and optimistic teacher are the most factors that positively affected to use package this result agreed with (Herman, 2012). Who stated that fortunately, instructor attitudes and class structures can support students' intrinsic motivation. Instructors who have high expectations and truly believe that their students can meet them are likely to provide the necessary support for student success. Similarly, when students feel instructors believe in their abilities, they often are more motivated to achieve.

From students' view, there is other factors related institution that included resources and physical environment reported by the majority of them that affected the use of self-directed learning, consequently to a shortage of computers which not permit to watch the educational videos and simulators which not let student a good chance to re-demonstrate the procedures by their own. Clearly, when students are intrinsically motivated to succeed, they will perform better in high cognitive tasks (Pink, 2011). The current study was agreed with (Flint \& Johnson, 2011) in his study about universities can provide extrinsic motivations to students, such as grades a positive campus environment, classes conditions, curriculum, and laboratories may be more important to determine ways to empower students to direct their own learning processes. By encouraging students to reflect on their own learning processes, evaluate the depth of knowledge they have on a subject, and identify areas that require further development.

At the same time, instructors' viewed that; clarity of aim of the package, its content\& student's language are very important factors affected the use of selfdirected learning. In addition, other factors from instructors' view regarding teacher abilities in participation \& explanation, and skill lab of the institution are important factors affected the use of self-directed learning.

This straightforward with (Douglass \& Morris, 2014) who studied student perspectives regarding self-directed learning and self-assessment he assumed that they are facilitated by professors and instructors who have clear and relevant grading structures, offering good instructions, clinical opportunities, are supportive of students and enthusiastic about teaching and learning. Good teachers know these are good practices, but what they may not know is how important students regard these actions to be in empowering self-directed learning and increasing the intrinsic motivation of their students.

Concerning to instructors and students recommendations to facilitate implementation selfdirected learning in education, The study revealed that clarity simple and well-organized content is a main recommendation, more over the instructors recommended that provide suitable time, institution administration, program innovation, and availability of rescores are another the main four recommendations. In addition to teacher abilities in explanation\& participation \& student motivation to learn and skill lab are the most important factors affecting the use of self-learning package.

Another finding of note is that not all students would be more motivated to engage in these processes if administrators provided incentives. This is an important reminder that "one-size-does-not-fit-all" when it comes to motivating students. Student motivation and success are unique experiences for each student (McCune \& Entwistle, 2011). In order to most effectively empower students in their own self-directed learning, institutions must directly ask students about their goals and plans (Guiffrida et al., 2013).

\section{Conclusions}

In the light of the present study finally concluded that: there are factors affecting to use of self-directed learning including clarity aim of the package \& clarity content, student's language abilities, teacher's explanation\& participation abilities, skill lab, resources, physical environment, and administrative facilities of the institution.

\section{Recommendations}

Nursing institution administrators must support teacher and student by creating an environment conducive to implement self-directive learning. 


\section{References}

1. Abdirahman M., Abubakar H., (2013): English Language Proficiency and Academic Achievement for Undergraduate Students in Somalia, Educational Research International, 22: 29.

2. Al Kadri H., Al-Moamary M., Elzubair M., Magzoub M., AlMutairi A., Roberts C., et al., (2011): Exploring factors affecting undergraduate medical students' study strategies in the clinical years: a qualitative study. Adv Health Sci Educ; 16:553_67.

3. Bandura A., (2001): Social cognitive theory: an agentic perspective. Annu Rev Psychol; 52: 1_26.

4. Bandura A., (2010): Self-efficacy: toward a unifying theory of behavioral change. Psychol Rev; 84: 191.

5. Bandura A., (2011): Self-efficacy. In: Ramachaudran VS, ed. Encyclopedia of human behavior. New York: Academic press; 4. pp. 71_81.

6. Boekaerts M., Pintrich P., Zeidner M., (2009): Handbook of self-regulation. Burlington: Elsevier;

7. Deci E., Ryan R., (2012). Handbook of selfdetermination research. Rochester, NY: University of Rochester Press;

8. Douglass, C., \& Morris, S., (2014): Student perspectives on self-directed learning, Journal of the Scholarship of Teaching and Learning, 14, No. 1 ,

9. Dunn K., Osborne C., Link H., (2012): Exploring the influence of students' attributions for success on their self-regulation in pathophysiology. J Nurs Educ; 51: 353.

10. Farrag R., (2010): Factors Affecting the use of Computer Based Method in Teaching Practical Skills for Nursing Students, Egyptian Journal of Health Care, 1:99-100.

11. Flint, N., \& Johnson, B., (2011): Towards fairer university assessment: Recognizing the concerns of students. New York: Routledge.

12. Guiffrida, D., Lynch, M., Wall, A., \& Abel, D., (2013): Do reasons for attending college affect academic outcomes? A test of a motivational model from a self-determination theory perspective. Journal of College Student Development, 54, 121-139.

13. Herman, G.L. (2012), Designing contributing student pedagogies to promote students' intrinsic motivation to learn. Computer Science Education, 22, 369-388.

14. McCune, V., \& Entwistle, N., (2011): Cultivating the disposition to understand in 21 st
Century university education, Learning, and Individual

15. Montalvo F., Torres M., (2010): Self-regulated learning: current and journal of research in educational psychology future directions.Electron J Res Educ Psychol; 2: 1_34. Differences, 21, 303-310.

16. Pintrich P., (2011): A conceptual framework for assessing motivation and self-regulated learning in college students. Educ Psychol Rev; 16: 385_407.

17. Pink, D., (2011): Drive: The surprising truth about what motivates us. New York: Riverhead Trade.

18. Ramnarayan K., \& Shyamala H., (2014): Thoughts on Self-Directed Learning in Medical Schools: Making Students More Responsible, Self-directed learning in population health. a clinically relevant approach for medical students, New Horizons for Learning Journal, X(2):69-70.

19. Randi J., (2011): Teachers as self-regulated learners. Teach Coll Rec 106: 1825_53.

20. Reeve, J., (2009): Why teachers adopt a controlling motivating style toward students and how they can become more autonomy supportive. Educational Psychologist, 44, 159-175.

21. Sandars J., Cleary T., (2011): Self-regulation theory: applications to medical education: AMEE Guide No. 58. Med Teach; 33:875_86.

22. Strage A., (2012) Family context variables and the development of self-regulation in college students. Adolescence; 33: 17_31.

23. Woods N., Mylopoulos M., Brydges R., (2011): Informal self-regulated learning on a surgical rotation: uncovering student experiences in context. Adv Health Sci Educ; 16: 643_53.

24. Zimmerman B., (2009)|: Self-regulated learning and academic achievement: an overview. Educ Psychol; 25: 3_17.

25. Zimmerman B., Pons M., (2010): Development of a structured interview for assessing student use of self-regulated learning strategies. Am Educ Res J 23: 614_28. 